\title{
INTERVENCIÓN DEL PROFESOR GIUSEPPE DE VERGOTTINI CON MOTIVO DE SU DOCTORADO HONORIS CAUSA ${ }^{1}$
}

\author{
GIUSEPPE DE VERGOTTINI
}

Excmo. y Magco. Sr. Rector de la Universidad Nacional de Educación a Distancia, Ilmo. Sr. Decano de la Facultad de Derecho, autoridades académicas, compañeros, miembros de la comunidad universitaria, señoras y señores,

Quiero ante todo agradecer al Profesor Don Antonio Torres del Moral, a la Profesora Doña Yolanda Gómez Sánchez, al Departamento de Derecho Constitucional y a la Facultad de Derecho haberme propuesto para el Doctorado Honoris Causa, a la Universidad Nacional de Educación a Distancia y a su Rector, Profesor don Alejandro Tiana Ferrer haberlo aceptado y al Profesor Don Pedro Tenorio Sánchez la amable Laudatio que acaba de pronunciar.

\section{UNA REFLEXIÓN SOBRE LAS PRESENTES TRANSFORMACIONES CONSTITUCIONALES.}

El año que acaba de comenzar presenta tanto en el ámbito europeo como a nivel de los estados particulares una situación general de incertidumbre que repercute también en nuestros regímenes constitucionales. Las reflexiones que brevemente expongo pretenden indicar solamente algunos de los puntos críticos que caracterizan la actual situación.

\footnotetext{
1 Traducción de Pedro Tenorio Sánchez
} 
Voy a comenzar haciendo algunas consideraciones acerca de la utilidad o no del concepto de transición para abordar este fenómeno. En segundo lugar, me referiré a algunas de estas incertidumbres en particular. Para acabar con unas breves conclusiones.

\section{1) Utilidad o no del concepto de transición}

Comenzando, pues, por plantearnos la utilidad o inutilidad del concepto de transición, la Unión Europea y los estados que forman parte de ella están atravesando un período de profundas incertidumbres y la mayor parte de los países que la componen siguen afectados por una crisis no solamente económica.

Todos somos conscientes del hecho de que muchas de las razones de optimismo que habían caracterizado al periodo que había visto la conclusión del segundo conflicto mundial y luego la superación de los dos bloques políticos contrapuestos ya están a nuestras espaldas. El futuro de nuestras instituciones y del régimen de los derechos que las caracterizan según las constituciones formalmente vigentes es incierto.

¿Se puede por tanto pensar que estamos en una fase de transición hacia un nuevo orden constitucional?

Intentar una respuesta a este interrogante es problemático, porque aun cuando es verificable que algunos cambios importantes están en marcha, no es sin embargo claro en absoluto cuál es el punto de llegada del cambio.

Pero, ¿estamos seguros de que sea utilizable a este propósito el concepto de transición?

El concepto utilizado por los politólogos tiende a referirse a procesos de cambio de un régimen prescindiendo del cambio formal de un texto constitucional

Para los constitucionalistas, la transición es una nebulosa no necesariamente identificable con el procedimiento de revisión. Los juristas, cuando la evocan, parecen en realidad pensar en un paso que ya ha tenido lugar. Es decir, piensan en lo que los politólogos califican como consolidación del recorrido en que consiste la transición

Pero debe quedar claro que cuando hay revisión de la Constitución, aunque sea profunda, no por este motivo hay transición entendida como cambio de régimen. Es paradigmático en este sentido el caso de la revisión total de la Constitución de Suiza del año 2000: se repensó profundamente el texto, pero ello no supuso cambio de los principios que identifican el régimen constitucional. Por tanto, en este caso, no hubo ninguna transición constitucional.

Si a título de ejemplo se me permite recordar el caso italiano, el recurso al concepto de transición debe ser utilizado con prudencia.

No ha existido en los años recientes paso alguno a una Segunda República (como se afirma a menudo, con una definición que tiene sólo valor periodístico) ni ninguna 
transformación en sentido federal. No se ha tocado la forma de estado. El ordenamiento constitucional ha sufrido una «mutación» constitucional. Ha habido el paso de un sistema de partidos a otro, de modo que ha incidido en el funcionamiento de la forma de gobierno. Parece por tanto admisible hablar de una «transición política», reconduciendo de esta manera la categoría al ámbito de la ciencia política, pero no una «transición constitucional».

Diría por tanto que la transición corre el riesgo de ser un concepto trampa, de convertir en incierta la frontera entre los cambios en curso y los consolidados, o de dar por descontado que existe un punto de llegada y de final de un recorrido. Pero no es así.

\section{2) Nuevas incertidumbres}

Por tanto, el recurso a la transición no ayuda a aclarar los términos de la actual situación. Si miramos a la situación del arte en Italia y en Europa, nos encontramos en un período con muchas incertidumbres e inestabilidad, y sólo en este sentido, para indicar procesos in fieri, podemos estar de acuerdo acerca de la posibilidad de utilizar una terminología nacida en el ámbito de los estudios politológicos.

Pasando a centrar nuestra atención en algunas de estas incertidumbres, voy a referirme, ante todo, a la situación de las instituciones de la Unión Europea. En segundo lugar, a las modificaciones de la forma de gobierno, con superación de la democracia de partidos. Y en tercer término, a la transformación del concepto de ciudadanía.

\section{Unión Europea}

Comenzando, pues, por la referencia a la Unión Europea, el estado de incertidumbre se comprueba también en la situación internacional.

El mantenimiento del marco institucional de la Unión Europea se pone en discusión cada vez más. Al tradicional problema de la discutida legitimidad de recuperaciones desordenadas de las soberanías de los estados se unen los clamorosos ejemplos de fracaso o de inadecuadas políticas sectoriales (política exterior, seguridad, migraciones, política económica y monetaria...).

Lo que impresiona es la extremada debilidad de la legitimidad de las instituciones europeas, comenzando por el propio Parlamento, que no es sentido como representativo por los diferentes cuerpos electorales nacionales. El propio Tribunal de Justicia de la Unión Europea, al posponer la adhesión al Convenio Europeo de Derechos Humanos, ha contribuido a agudizar un régimen de incertidumbre. También a nivel de Consejo de Europa el recurso al margen de apreciación hace difícil una visión armónica de las tutelas de los derechos a nivel europeo, dejando amplio espacio a los estados para intervenir como crean mejor en el aseguramiento de la protección de los derechos culturales y sociales. 
A una carencia de legitimidad de los órganos político administrativos que expresan la integración sustituye una fuerte legitimidad de la jurisdicción europea. Pero aquí se manifiesta una particular quiebra del proceso de legitimación del conjunto de las instituciones. La legitimidad del Tribunal de Justicia no se debe atribuir a los pueblos de los estados miembros, que en realidad lo ignoran. El sujeto colectivo que lo legitima es el estrato de los juristas que debe enfrentarse con el complicado laberinto de competencias entre jurisdicciones nacionales, celosas de la soberanía de los estados respectivos, y jurisdicción comunitaria, puesta en el vértice de los vínculos queridos por los tratados. La fuerte legitimidad del Tribunal de Justicia permanece a pesar de la crisis evidente que afecta a la Unión.

Si el diseño del espacio jurídico europeo (derecho público europeo) sobrevive, es también porque los tribunales nacionales mantienen un enfoque de colaboración sobre la base de una relación de confianza recíproca con el Tribunal de Justicia y con el de Estrasburgo.Puede parecer curioso que a la escasa legitimidad atribuida por los ciudadanos europeos a las instituciones corresponda al menos por parte de los tribunales y de los juristas una fuerte legitimidad de la jurisprudencia europea.

Por tanto, la legitimidad que los jueces nacionales continúan constantemente dispensando al Tribunal de Justicia compensa la profunda crisis del prestigio institucional de los órganos político-administrativos, que solamente subsiste para el órgano intergubernamental.

Modificaciones de la forma de gobierno y superación de la democracia de partidos

En lo atinente a las modificaciones de la forma de gobierno y superación de la democracia de partidos, se puede detectar una creciente «presidencialización» de las estructuras de gobierno, comprendidas las formas parlamentarias, con la aparición de una forma de gobierno en la que los problemas clásicos de la legitimidad y de la limitación del poder que han constituido el punto de apoyo de la palanca del constitucionalismo históricamente, son colocados en posición de retroceso.

Sin duda, estos factores indican la actuación de una mutación profunda desde la perspectiva política y constitucional, pudiendo discutirse sobre el hecho de que estemos ante una transición destinada a poner de manifiesto una verdadera y propia incapacidad de la opción constitucional de los años cuarenta del siglo pasado o bien de una compleja transición crítica que, sin embargo, no niegue los fundamentos del ordenamiento estatal.

La democracia de partidos de la que se han nutrido nuestros estudios en los pasados años parece ya un dato remoto sustituida por la más actualizada democracia del público, en la que los partidos ceden espacio a la personalización, la organización a la comunicación, al tiempo que las identidades colectivas se debilitan, compensadas por la confianza personal directa, sobre todo en la figura del leader. Éste es el dato que se ha 
convertido en una de las características centrales en el desarrollo más reciente de las instituciones y, de rechazo, en el debate científico.

El papel reforzado de un leader se sitúa en un marco más amplio, que contempla el debilitamiento del papel mediador tradicional de los partidos y de la representación residenciada en las asambleas representativas. La caída de la intermediación de los partidos tiene como consecuencia inevitable la emergencia de fuertes liderazgos personales. Esto es facilitado por los medios actualizados de comunicación política. Y en efecto, como acabamos de señalar, los candidatos vencedores son las llamadas «figuras mediáticas». Añádase la afirmación del modelo plebiscitario, en el que el predominio de la demanda (las pulsiones emotivas de la gente) es sólo aparente, mientras que el predominio de la oferta, esto es, de la voluntad del leader, es bastante real.

Debe subrayarse que en Italia el cese del eje partidos-representación-Parlamento es particularmente acentuado, conduciendo así al sistema político a gravitar sobre el gobierno y a este último a concentrarse en la figura del jefe del ejecutivo. Por tanto, es verdad que ha desaparecido la «sociedad de clase» del siglo xx y con la misma aquel sistema de partidos que constituía la proyección institucional de la misma. Han entrado así en crisis los complejos mecanismos de la representación político democrática, entendida como proceso político y como relación que se desenvuelve en el tiempo, expresando un vínculo permanente entre la sociedad y los elegidos, con la asamblea representativa como lugar en que unificar la pluralidad de los intereses representados para dar forma política a una sociedad cada vez más compleja y fragmentada.

La demostrada incapacidad de las instituciones tanto nacionales como europeas para afrontar y resolver la dramática crisis económica, con la consiguiente insatisfacción generalizada hacia la gestión de la política llevada a cabo por los actores tradicionales, ha generado una actitud hostil a la representación política tradicional, que caracteriza a una especie de contrapolítica basada en el control, la oposición, la humillación de los poderes previstos por las vigentes constituciones democrático liberales.

Los partidos tradicionales han desaparecido, o en la mejor de las hipótesis, permanecen como una sombra de lo que fueron en el pasado. Toman por tanto la iniciativa movimientos y partidos populistas que, según una interpretación difundida, se dirigen al pueblo identificado en los estratos sociales económicamente más humildes y sobre todo culturalmente más atrasados. Estos movimientos hacen palanca, una y otra vez, en valores negativos, como la corrupción, la crisis económica, el antieuropeísmo, pero también en una hipotética identidad cultural, étnica y/o religiosa, asumiendo en tal caso tonos nacionalistas y racistas. En sustancia, se unen por la contestación radical de la democracia representativa.

En esta forma política, que parece estar consolidándose, el pueblo es algo muy distinto del pueblo formado por un agregado de impulsos heterogéneos que permiten la generación de una fuerte orientación política nacional. El pueblo ya no sería el considerado en la Constitución como titular último de la soberanía. El pueblo actual es caracterizado de manera aduladora como depositario de todas las virtudes sociales y como víctima del cínico egoísmo y de la amoralidad de los degradados estratos 
dominantes. En su favor, se formulan propuestas políticas idóneas para gratificar el deseo de cuestionamiento por parte del propio pueblo, pero no idóneas para incidir eficazmente en los complejos problemas de la sociedad moderna. Estas propuestas se desenvolverían de manera instrumental, porque en lo sustancial están orientadas a perseguir fines de mera conquista o mantenimiento del poder por parte de los nuevos sujetos políticos en vía de consolidación. Resultado de tal proceso es no solamente la confirmación de la profunda crisis de los viejos partidos, sino la perspectiva del definitivo colapso de los mismos.

Sobre estas premisas, resulta verdaderamente problemático pensar de manera realista en una especie de renacimiento del partido tradicional entendido, entre otras cosas, como canal de conexión entre base social y asambleas representativas. Desde esta perspectiva, se ha hablado de una reconsideración de la forma partido y de la necesidad de tener partidos «ligeros» pero que funcionen, con procedimientos democráticos tanto para la elección del leader (y para la activación de su responsabilidad) sea para la determinación de los candidatos a los cargos públicos, con métodos de selección interna garantizados o con elecciones primarias. En tal sentido, se vuelve de vital importancia construir formaciones políticas que estén en condiciones, ciertamente, de mantener al leader, pero también de hacerlo políticamente responsable y de sustituirlo cuando esto se vuelva necesario, so pena de una inaceptable especie de desinstitucionalización de la figura misma. Añádase que junto a la reflexión sobre el papel de los partidos se vuelve esencial retomar también el debate acerca de una regulación de los lobbies y de los grupos de presión, en razón de su papel de actores políticos.

Transformación del concepto de ciudadanía

Y con esto paso a referirme al tercer ámbito de incertidumbre, la Transformación del concepto de ciudadanía.

Una gran mutación ha tenido lugar y está todavía in fieri con referencia al nuevo papel asumido por el extranjero en cuanto migrante proveniente de áreas culturales distintas con el propósito de permanecer durante algún tiempo o definitivamente en el territorio que lo acoge. La tendencia evidente opera en la dirección de una progresiva ineluctable superación de la ciudadanía histórica vinculada al territorio (y por tanto al principio de soberanía territorial estatal) como estatus jurídico de titularidad potencial de derechos y deberes propios solamente del tradicional ciudadano en cuanto íntimamente vinculado a una cierta soberanía estatal.

Con ciertos requisitos el extranjero se convierte en una componente obligada de la realidad social. El nexo indispensable para el mantenimiento de conjunto del ordenamiento parece conducir a una concepción de la ciudadanía de tipo diverso de la política, a la que se añade sin sustituirla. Es la «ciudadanía social», que reconoce el nivel mínimo de garantía de los derechos atribuible al extranjero. 
Por tanto, se comprende que, si el mismo concepto de ciudadanía muta, desvinculándose en cierta medida del vínculo con el territorio para perseguir un fin social que ya no puede incluir a la compleja figura del migrante, como consecuencia también toda la estructura institucional está destinada a mutar en los aspectos en que no haya mutado ya.

El extranjero se ha convertido en verdaderamente central en las políticas legislativas de los estados. Y esto con base en opciones internas, pero sobre todo en virtud de tratados internacionales.

Es necesario sin embargo subrayar que los tratados internacionales reconocen derechos, pero al mismo tiempo establecen límites que dejan a la protección del tradicional ordenamiento soberano.

La expansión de las migraciones, con la presencia de nuevas comunidades de cultura, frecuentemente lejana de la europea, implica el cuestionamiento de la ciudadanía por medio de la extensión de los derechos más allá de la barrera de la ciudadanía estatal tradicional, pero hace también aflorar a la superficie de manera dramática la incompatibilidad de parte de los valores de los que los migrantes son portadores con aquellos irrenunciables previstos en las constituciones y en las cartas de derechos europeas.

Existe un sólido núcleo de principios europeos unificadores y parece verdaderamente problemático que no ponga dique a valores culturales incompatibles con él. Por tanto, tolerancia y respeto a la diversidad no pueden sino encontrar en los valores constitucionales irrenunciables fronteras necesarias al proceder a la solución de todos los casos de irremediable contradicción entre culturas también jurídicas. Y esta exigencia parece plantearse como moderadora inevitable de la amplitud de la ampliación de los derechos de los extranjeros.

En este panorama, hablar de multiculturalismo referido a la presencia de una multiplicidad de concepciones culturales que comprenden a las culturas jurídicas diversas es perfectamente lícito y no plantea problemas.

Estos surgen sin embargo cuando se prescinde del simple reconocimiento de la diversidad y tiene lugar una colisión entre distintas culturas que pretenda aproximar o incluso imponer una cultura a otra debiéndose constatar que las mismas no se manifiestan siempre como compatibles. Es a esta faceta conflictual del multiculturalismo a la que nos referimos cuando sujetos parte de una cultura distinta de la de una mayoría dominante, y por tanto minoritarios, invoca una excepción a la concepción prevalente de los valores de modo que quede a salvo la manera propia de concebir la garantía de los derechos fundamentales.

En este punto, tanto en el ámbito político como en el doctrinal, se manifiesta en Europa un dramático interrogante que se refiere al nivel de transigencia de los principios que tutelan en los diferentes estados la identidad cultural nacional para permitir la tutela de las multiformes y compuestas identidades de las comunidades de extranjeros que progresivamente se enraízan en el territorio estatal. 


\section{3) En conclusión}

Como recapitulación y conclusión quisiera hacer las siguientes consideraciones.

La crítica actual de la situación de nuestros países se presta a dar acceso a un vasto abanico de problemas que interesan desde hace tiempo no sólo en el ámbito social, económico y político, sino también jurídico.

Los constitucionalistas desde siempre siguen el desarrollo de nuestras instituciones en las que la experiencia nacional se imbrica continuamente con la europea y más ampliamente internacional. La expansión de las migraciones con la presencia de nuevas comunidades de cultura a menudo lejana de la europea, implica el cuestionamiento de la ciudadanía mediante la extensión de los derechos más allá de la barrera de la ciudadanía estatal tradicional, pero hace también aflorar de manera dramática la incompatibilidad de parte de los valores de los que los migrantes son portadores con los irrenunciables previstos por las constituciones y por las cartas de derechos europeas.

El desarrollo de la investigación produce nuevos conocimientos y nuevas modalidades de afrontar y satisfacer necesidades consideradas esenciales para el hombre en el ámbito sanitario y ambiental. Al mismo tiempo, nos lleva a preguntarnos sobre la compatibilidad de tales innovaciones con un concepto consolidado de dignidad de la persona.

En el ámbito político social, las instituciones quedan afectadas por maneras nuevas de concebir la política sobre todo por lo que se refiere a la validez o no del concepto tradicional de representación, que supondría la permanencia del papel de los partidos como conexión entre ciudadanos e institución parlamentaria. Al mismo tiempo, la ruidosa aparición en el escenario político de movimientos populistas y la prevalencia del recurso a las técnicas de comunicación mediática más actualizadas están consolidando una concepción del liderazgo político personal muy lejana de la idea del gobernante que se confronta con la oposición en el aula parlamentaria, única sede institucional en la que comprometer la responsabilidad política. Todo ello en un escenario institucional que ha visto en pocos años degradarse rápidamente la construcción de la Unión Europea, cuya problemática legitimidad subsiste solamente gracias al prestigio de la jurisprudencia de los tribunales supranacionales, que continúa siendo apoyada por la tenacidad con la que el estrato de los juristas ha decidido no abandonar el ideal de la integración.

Muchas gracias. 